\title{
An interesting case of postprandial hypoglycaemia
}

Ishwar Bhattarai, Cheuk Mun Au

\section{CASE}

A woman aged 55 years presented to her general practitioner with intermittent episodes of dizziness, sweating and shakiness for the past four months. These episodes lasted for a few minutes and resolved spontaneously or after lying down. Lately, these episodes had become more common, especially after sugary meals. She had no chest pain, breathlessness or loss of consciousness during these episodes. Her medical history included anxiety, asthma, type 2 diabetes and obesity, for which she had undergone gastric bypass surgery three years ago. She was a non-smoker who drank alcohol socially. Her only medication was escitalopram $20 \mathrm{mg}$ daily. Her clinical examination was unremarkable and vital signs were normal. Her body mass index was $32 \mathrm{~kg} / \mathrm{m}^{2}$.

\section{QUESTION 1}

What are the provisional and differential diagnoses?

\section{QUESTION 2}

What is dumping syndrome and what are its causes?

\section{QUESTION 3}

What is the pathophysiology of dumping syndrome?

\section{QUESTION 4}

How is dumping syndrome diagnosed?

\section{ANSWER 1}

The provisional diagnosis is dumping syndrome. Other differentials are:
- postprandial hypotension

- pheochromocytoma

- insulinoma

- carcinoid syndrome

- functional neurological disorder.

\section{ANSWER 2}

Dumping syndrome is a cluster of gastrointestinal and vasomotor symptoms due to rapid gastric emptying after a meal. Dumping syndrome is classified as early and late type. Early dumping syndrome presents within 30 minutes of a meal, and symptoms include palpitations, fatigue, sweating, lightheadedness, hypotension, abdominal fullness, nausea and diarrhoea. Late dumping syndrome occurs 1-3 hours after a meal and is an incretin-driven hyperinsulinaemic response. ${ }^{1}$ This leads to reactive hypoglycaemia, which presents with adrenergic and neuroglycopenic symptoms such as tremor, sweating, anxiety, fatigue, hunger and confusion. ${ }^{1}$

Dumping syndrome is common after bariatric surgeries such as gastric bypass or sleeve gastrectomy. ${ }^{2}$ There are cases of dumping syndrome associated with non-surgical causes such as diabetes mellitus. ${ }^{3,4}$

\section{ANSWER 3}

Dumping syndrome is typically due to rapid transit of gastric chyme into the intestinal lumen. This leads to intestinal distension and release of many gastric hormones. These hormones decrease splanchnic vascular resistance, shifting fluids from general circulation to gastrointestinal (GI) circulation, ${ }^{5}$ which leads to vasomotor symptoms such as hypotension, fatigue, dyspnoea and faintness. Sympathetic activation then causes palpitations and sweating.
In late dumping syndrome, rapid transit of gastric chyme causes the release of other GI hormones such as gastric inhibitory peptide and glucagon-like peptide. ${ }^{3,4}$ These hormones stimulate the release of insulin from the pancreas, leading to reactive hypoglycaemia manifested as sweating, palpitations, light-headedness and fainting.

\section{ANSWER 4}

A classic presentation with a history of gastric surgery is highly suggestive of dumping syndrome. There is a symptomsbased scoring system available to diagnose dumping syndrome (Table 1$).{ }^{6}$ An oral glucose tolerance test (OGTT) is typically confirmatory; however, there is risk of severe hypoglycaemia, so it is advisable that the test is conducted under clinical supervision. A haematocrit rise of $3 \%$ or an increase in pulse rate $>10$ beats $/ \mathrm{min}$ after 30 minutes is suggestive of early dumping syndrome, while hypoglycaemia after 2-3 hours of glucose ingestion suggests late dumping syndrome. ${ }^{7}$ A gastric emptying test using radionuclide scintigraphy can demonstrate rapid gastric emptying quantitatively. ${ }^{8}$

\section{CASE CONTINUED}

The patient underwent an OGGT; the results are shown in Table 2. Her thyroid, kidney and liver functions and electrolytes were within normal limits. She was diagnosed with late dumping syndrome.

\section{QUESTION 5}

What is the treatment for dumping syndrome? 


\section{ANSWER 5}

Lifestyle and dietary modifications are the first-line treatment for dumping syndrome. Smaller and more frequent meals of low-calorie dense food help to control the symptoms. ${ }^{1} \mathrm{~A}$ high-fibre diet of unprocessed carbohydrates and low glycaemic index food can stabilise blood glucose fluctuation as seen in late dumping syndrome. Other dietary modifications

\section{Table 1. Sigstad score: A score of $\geq 7$ is highly suggestive of dumping syndrome $^{6}$}

\begin{tabular}{lr}
\hline Symptom & Score \\
\hline Pre-shock or shock & +5 \\
\hline Loss of consciousness, fainting & +4 \\
\hline Desire to lie down or sit & +4 \\
\hline Dyspnoea & +3 \\
\hline Physical fatigue, exhaustion & +3 \\
\hline Sleep, listlessness, blurred vision & +3 \\
\hline Palpitation & +3 \\
\hline Restlessness, agitation & +2 \\
\hline Dizziness, vertigo & +2 \\
\hline Headache & +1 \\
\hline Feeling hot, sweating, paleness, & +1 \\
\hline clammy skin & +1 \\
\hline Nausea & +1 \\
\hline Abdominal distension, meteorism & +1 \\
\hline Borborygm & +1 \\
\hline Eructation & -1 \\
\hline Vomiting & +1 \\
\hline
\end{tabular}

Table 2. Oral glucose tolerance test results

\begin{tabular}{lrr}
\hline Time & $\begin{array}{r}\text { Glucose } \\
\text { (mmol/L) }\end{array}$ & $\begin{array}{r}\text { Reference range } \\
\text { (mmol/L) }\end{array}$ \\
\hline Fasting & 4.4 & $3.0-6.0$ \\
\hline One hour & 9.3 & $<10$ \\
\hline Two hours & 2.0 & Up to 7.7 \\
\hline
\end{tabular}

include avoiding liquids within 30 minutes of solid food meals, avoiding simple sugars (juices/lollies) and processed caloriedense foods (donuts/chocolate), and increasing intake of protein.

Pharmacological interventions are reserved for severe cases uncontrolled by lifestyle and dietary modifications. Currently available options are alpha-glucosidase inhibitors (eg acarbose) and somatostatin analogues (eg octreotide). ${ }^{9}$ Acarbose inhibits alpha-glucosidase in the small intestine and delays the intraluminal digestion of carbohydrates that leads to insulin surge and reactive hypoglycaemia. ${ }^{9}$ Octreotide improves dumping syndrome by multiple mechanisms: delaying gastric emptying, slowing small intestine transit and decreasing release of gastrointestinal hormones including insulin secretion. ${ }^{1,9}$

\section{CASE CONTINUED}

The patient was referred back to her bariatric dietician for dietary modification. Her symptoms improved significantly over the following three months with lifestyle and dietary modifications.

\section{Key points}

- Dumping syndrome is common after bariatric surgeries.

- Reactive hypoglycaemia is a typical feature of late dumping syndrome.

- An OGTT and gastric scintigraphy are diagnostic tests.

- Management is based on lifestyle and dietary modification, failure of which necessitates medication such as acarbose or octreotide.

\section{Authors}

Ishwar Bhattarai MBBS, MS, DCH, FRACGP, General Practitioner, Murgon Family Medical Practice, Qld Geriatric Fellow, Washington Health System, USA Cheuk Mun Au BMedSci, MBBS, FRACGP, General Practitioner, Gatton Medical Centre, Qld Competing interests: None.

Funding: None.

Provenance and peer review: Not commissioned, externally peer reviewed.
Correspondence to:

bhattarai.ish@gmail.com

\section{References}

1. van Beek AP, Emous M, Laville M, Tack J. Dumping syndrome after esophageal, gastric or bariatric surgery: Pathophysiology, diagnosis, and management. Obes Rev 2017:18(1):68-85. doi: 10.1111/obr.12467.

2. Abell TL, Minocha A. Gastrointestinal complications of bariatric surgery: Diagnosis and therapy. Am J Med Sci 2006;331(4):214-18 doi: 10.1097/00000441-200604000-00008.

3. Altuntaş Y. Postprandial reactive hypoglycemia. Sisli Etfal Hastan Tip Bul 2019;53(3):215-20. doi: 10.14744/SEMB.2019.59455.

4. Berg P, McCallum R. Dumping syndrome: A review of the current concepts of pathophysiology, diagnosis and treatment. Dig Dis Sci 2016;61(1):11-18. doi: 10.1007/s10620-053839-x.

5. Aldoori MI, Qamar MI, Read AE, Williamson RC. Increased flow in the superior mesenteric artery in dumping syndrome. Br J Surg 1985;72(5):389-90. doi: 10.1002/bjs.1800720518.

6. Sigstad H. A clinical diagnostic index in the diagnosis of the dumping syndrome. Changes in plasma volume and blood sugar after a test meal. Acta Med Scand 1970;188(6):479-86.

7. van der Kleij FG, Vecht J, Lamers CB, Masclee AA. Diagnostic value of dumping provocation in patients after gastric surgery. Scand J Gastroenterol 1996;31(12):1162-66. doi: 10.3109/00365529609036905

8. Tougas G, Eaker EY, Abell TL, et al. Assessment of gastric emptying using a low fat meal: Establishment of international control values. Am J Gastroenterol 2000;95(6):1456-62. doi: 10.1111/j.1572-0241.2000.02076.x.

9. Vavricka SR, Greuter T. Gastroparesis and dumping syndrome: Current concepts and management. J Clin Med 2019;8(8):1127. doi: $10.3390 / \mathrm{jcm} 8081127$. 